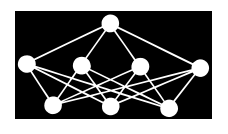

\title{
MODIFIED METHOD OF GRAVITY MODEL APPLICATION FOR TRANSATLANTIC AIR TRANSPORTATION
}

\author{
Helena Bínová*
}

\begin{abstract}
Air transportation between Europe and the U.S. is becoming more and more significant. It can only hardly be replaced by other means of transportation, since its biggest advantages include speed and reliability. Air transportation forecasting is important for planning the development of airports and related infrastructure, and of course also for air carriers. Therefore, it is important to forecast the number of flights between selected airports in Europe and the U.S. and the number of transported persons. A gravity model is usually used for this forecasting. Determination of coefficients which significantly affect results of the formulas used in the gravity model is crucial. Coefficients are, as a rule, computed by an iterative algorithm implementing the gradient method. This technique has some limitations if the state space is inappropriate. Moreover, the exponent parameter in the formula is obviously fixed. We have chosen the new method of differential evolution to determine the gravity model coefficient. Differential evolution works with populations similarly to other evolution algorithms. It is suitable for solving complex numerical problems. The suggested methodology can be helpful for various airlines to forecast demand and plan new long-haul routes.
\end{abstract}

Key words: Air transportation, development, forecasting, gravity model, transatlantic flights, differential evolution

Received: October 3, 2014

DOI: $10.14311 /$ NNW.2015.25.011

Revised and accepted: April 15, 2015

\section{Introduction}

Aviation-related planning and services need to continuously be improved so that operations can be more efficient and profitable. Commercial air transportation is important in connecting people and businesses in the world.

Transatlantic long-haul flights fly regularly from Europe to North America, South America, the Far East and Australia, Africa and vice versa, already since the beginning of commercial aviation in 1939 .

This paper describes the possibilities of current data analysis methodology, which can help identify the main factors that influence passenger demand for the transatlantic route network.

\footnotetext{
*Helena Bínová, CTU Prague, Faculty of Transportation Sciences, Department of Logistics and Management of Transport, Konviktská 20, Prague 110 00, Czech Republic, E-mail: binova@fd.cvut.cz
} 
Passengers obviously demand airlines operating on the most direct routes, with comfortable aircrafts and inexpensive tickets. The required reliability and safety of flights is also gradually on the rise. Airlines should follow these trends and try to enhance passenger's experience and achieve a high level of passenger satisfaction.

Aviation as a specific branch of industry is very dynamic. Positive external factors include, for example, technological development, development of infrastructure and Air Traffic Management (ATM). Negative factors include, for example, capacity limits, airport congestion, oil crisis, global airline deregulation, terrorist attacks and political instability.

Route forecasting is one of the numerous decision support tools created by airlines and represents a critical part of profitable network planning. Especially the identification and forecasting of a new market and associated revenue can potentially lead to an increase of the profit of the respective airline. This could lead to increased passenger demand from the new market. Airline route decisions can be made simply based on an individual's judgment based on experience, but this becomes more difficult when the number of routes as well as the size of the airline increase. Then it is necessary to choose an appropriate model to forecast demand and plan new routes.

The number of passengers which travel between airports in a specific time interval is usually estimated using the gravity model. The parameters (also referred to as constants) of this model are frequently calculated with iterative algorithms implementing the gradient method.

The gravity model predicts movement of persons, information and goods between cities, or even between continents. Hence these models measure intensity of relations between 2 objects (small relations between small objects, large relations between large ones). In terms of traffic network management, the gravity models are used for managing the impact of technical and economic parameters of the individual traffic network sections.

In air transportation forecasting, there exists a gravity model for analyzing passenger demand, described by Chang [2]. The formula is:

$$
T_{i j}=\frac{C \cdot P_{i} \cdot A_{j}}{f\left(d_{i j}\right)},
$$

where:

$T_{i j} \quad$ represents the number of trips produced in country $i$ (origin) and attracted to country $j$ (destination) as the force between the masses,

$C$ is a constant,

$P_{i} \quad$ represents the production factors of country $i$,

$A_{j} \quad$ represents the attracting factors of country $j$,

$d_{i j} \quad$ is the distance between country $i$ and country $j$.

This article uses a modified gravity model with Cheu's gravity model formula [3], in which the Eq. (1) is rewritten into the specific form:

$$
T_{i j}=a_{i} b_{j} \frac{\mathrm{POP}_{i} \cdot \mathrm{BUS}_{j}}{\mathrm{DIS}_{i j}^{x}},
$$

where: 
$\mathrm{POP}_{i}$ is the population of origin airport $i$,

BUS $_{j}$ is the business or attractiveness of destination airport $j$,

$\operatorname{DIS}_{i j}$ is the distance between the airport of origin $i$ and the destination $j$ and it is used as the impedance of travel between $i$ and $j$,

$T_{i j} \quad$ is the predicted number of flights between origin airport $i$ and destination $j$,

$a_{i} \quad$ is an airport specific trip production constant,

$b_{j} \quad$ is an airport specific trip attraction constant.

$a_{i}, b_{j}$ and the exponent $x$ are parameters of the model and they need to be calibrated.

The initial value $x$ is set to 2 and parameters $a_{i}, b_{j}$ are computed via an iterative algorithm [3, 12], as follows:

$$
\begin{aligned}
\text { Assume all } & a_{i}=1, \\
\text { calculate all } & b_{i} \text { using } b_{j}=\left[\sum_{i=1}^{n} \frac{a_{i} \mathrm{POP}_{i}}{\operatorname{DIS}_{i j}^{x}}\right]^{-1}, \\
\text { calculate all } & a_{i} \text { using } a_{i}=\left[\sum_{j=1}^{n} \frac{b_{j} \mathrm{BUS}_{j}}{\operatorname{DIS}_{i j}^{x}}\right]^{-1}, \\
\text { calculate } & T_{i j}=a_{i} b_{j} \frac{\operatorname{POP}_{i} \operatorname{BUS}_{j}}{\operatorname{DIS}_{i j}^{x}} \text { for all } i \text { and } j .
\end{aligned}
$$

Steps (3), (4) and (5) are repeated until $a_{i}, b_{j}$ and $T_{i j}$ converge. The result of the application of a gravity model is a demand matrix $\mathbf{T}\left(T_{i j}\right.$ is one of elements of this matrix). In this paper, parameters used in gravity model are determined using the method of differential evolution.

Differential evolution is a relatively new type of evolutionary algorithms (since 1994). There are many algorithms that are classified as evolutionary, for example Genetic Algorithms, Ant Colony Optimization, Scatter Search, Immunology System Method. Each algorithm is suitable for solving a certain class of problems. Hence it is important to test and decide for which set of problems the algorithm is applicable and which approach fits best to the respective task.

The algorithm of differential evolution is demonstrated on the real flight prediction problem applied to six European airports as origins and six U.S. airports as destinations.

\section{Differential evolution}

Differential evolution (DE) is one of many evolutionary techniques. It was created by R. Storn and K.V. Prince in the nineties $[6,12]$. It is suitable for numerical optimisation problems. Basic advantages of differential evolution are:

- simplicity,

- heterogeneity of representation (integers, float numbers), 
- running time of the algorithm,

- independence of parent quality - three parents are selected for reproduction randomly $[6,9]$,

- good ability to find an extreme,

- efficiency of non-linear problem solving with boundaries.

\subsection{Description of the DE algorithm}

Similarly to other evolutions algorithms, DE works with populations, where a population is a set of individuals in simulation time $t$ and each individual is one solution of the problem. The principle of population creation and parameter setting is similar to other evolutionary techniques. The population can be represented as an $N P \times D$ matrix, where $N P$ is population size and $D$ is the dimension (the number of parameters of the individual).

In other words, columns of the matrix are individuals, and each individual is a one-dimensional vector having $D$ components. Each individual within the population is marked as $J_{i}(i=1 \ldots N P)$. The quality of each individual is estimated by the calculation of the fitness function, which measures also the individual's suitability for subsequent evolution (the result of the fitness function is called CV cost value).

\section{Parameters and terminology}

The algorithm of differential evolution is parameterized by the following parameters:

- Crossover threshold CR - the probability of noisy vector selection. Each component of the testing vector is set to the component of a noisy vector with probability $\mathrm{CR}$ and to the component of the parent $\mathrm{r}_{4}$ otherwise. The recommended value is $\mathrm{CR} \in\langle 0.8-0.9\rangle[6]$.

- The size of the population (the count of individuals in the population) $N P$, with a recommended value of $N P \in\langle 2 D, 100 D\rangle$ where $D$ is the dimension of the individual.

- Mutation constant $F$ is used as multiplicative constant in the noisy vector creation process. The recommended value is $F \in\langle 0,2\rangle[6]$.

- Maximum count of iterations MAX_ITERATION - the number of evolution cycles after which the algorithm stops.

The algorithm can be described as follows:

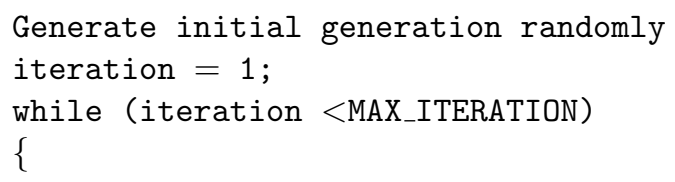




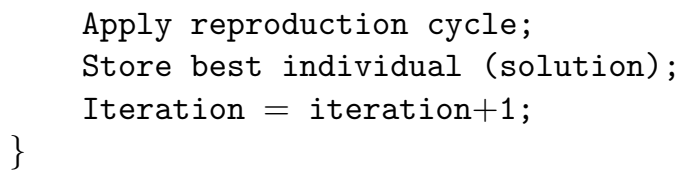

\section{Reproduction cycle}

The individual is represented as a vector with $D$ components. Denote each component as $x_{j}=1 \ldots D ; x_{i j}$ is the $j$-th component of the $i$-th individual.

A noisy vector is a vector $\mathbf{v}=\left(v_{1}, \ldots, v_{D}\right)$ and the "testing" vector is $\mathbf{z}_{\mathbf{v}}=$ $\left(z_{v 1}, \ldots, z_{v D}\right)$.

For each individual $J_{i}$ in population $(i=1 \ldots N P)$.

\{

Select randomly 4 parents $r_{1}, r_{2}, r_{3}, r_{4}$ from the population other than $J_{i}$

$/ /$ noisy vector $\mathbf{v}$ creation

for $j=1$ to $D$ do $v_{j}=x_{r 3, j}+F\left(x_{r 1, j}-x_{r 2, j}\right)$;

$/ /$ testing vector $\mathbf{z}_{\mathbf{v}}$ creation

for $j=1$ to $D$ do

if $(\operatorname{rand}()<\mathrm{CR}) z_{v j}=v_{j}$; else $z_{v j}=x_{r 4, j}$;

//calculate a fitness value $\mathrm{CV}$ of testing vector

fit $=$ fitness $\left(\mathbf{z}_{\mathbf{v}}\right)$;

if $\left(\operatorname{fit}\left(\mathbf{z}_{\mathbf{v}}\right)\right.$ is better than $\left.\operatorname{fit}\left(J_{i}\right)\right)$

copy $\mathbf{z}_{\mathbf{v}}$ into interpopulation into $i$ position;

else

copy original individual $J_{i}$ into interpopulation into $i$ position \}

Replace population by interpopulation.

Note: Function rand() generates a random value between 0 and 1 with uniform distribution.

\subsection{Application of differential evolution to the specific issue}

DE was tested on a task with six departing airports in Europe and six destination airports in the U.S.

\subsubsection{Airport selection}

The process of selecting airports for future development of demand forecasting methodology was conducted by a qualitative method. First, the judgment method was used to investigate six airports in the U.S.: New York (JFK), Boston (BOS), Chicago (ORD), Miami (MIA), Los Angeles (LAX) and San Francisco (SFO). A few airports in Europe that have competing flights with Prague and passengers from Prague usually take connecting flights from Prague via these cities to the 
U.S.: Vienna, Frankfurt, Paris, London, Amsterdam, Copenhagen, and Zurich, supported by market analysis from Prague Airport, worldwide statistics and current situation of PRG.

\begin{tabular}{|c|c|}
\hline IATA code & European Airports \\
\hline AMS & Amsterdam Airport Schiphol \\
\hline BUS & Budapest Liszt Ferenc Inter. Airport \\
\hline CDG & Charles De Gaulle Airport \\
\hline FRA & Frankfurt am Main Airport \\
\hline LHR & Heathrow Airport \\
\hline PRG & Vaclav Havel Airport Prague \\
\hline VIE & Vienna International Airport \\
\hline ZRH & Zurich Airport \\
\hline
\end{tabular}

Tab. I Final result of selection of European airports.

\begin{tabular}{|c|c|}
\hline IATA code & European Airports \\
\hline BOS & Logan International Airport \\
\hline JFK & John F. Kennedy International Airport \\
\hline LAX & Los Angeles International Airport \\
\hline MIA & Miami International Airport \\
\hline ORD & Chicago O'Hare International Airport \\
\hline SFO & San Francisco International Airport \\
\hline
\end{tabular}

Tab. II Final result of selection of U.S. airports.

\subsubsection{Input data}

There are two types of variables:

- Dependent (predicted) variable is the number of passengers (passenger trips) on an airport-pair route during a set period (typically).

- Independent variables are related mainly to two factors [11]:

- Geo-economic factors / economic activity,

- Geographical factors / location impacts.

Based on availability of historical data and previous research [2], ten variables are statistically significant in determining passenger flows between airport pairs (Tab. VI).

Data collection - demand data, supply data (airline schedules), economical (or geo-economical) data.

Demand data were obtained based on the total number of passengers travelling from Prague Airport to the various U.S. airports in 2011, and the same also applies 
Bínová H.: Modified Method of Gravity Model Application...

\begin{tabular}{|c|c|c|}
\hline Code & Dependent variables & Description \\
\hline $\mathrm{PAX}$ & Number of passengers & $\begin{array}{l}\text { Number, one-way from European } \\
\text { to U.S. airports }\end{array}$ \\
\hline Code & Independent variables & Description \\
\hline POP & Population & Number, in 2011 \\
\hline UER & Unemployment rate & $\%$, in 2011 \\
\hline DIS & Distance & $\begin{array}{l}\text { Distance between two selected } \\
\text { cities, in air miles }\end{array}$ \\
\hline TPAX & Total passengers of the airport & Total passengers handled in 2011 \\
\hline NIPC & National income & $\begin{array}{l}\text { US\$ (per capita) of the destination } \\
\text { city in } 2011\end{array}$ \\
\hline BUS & Business & $\begin{array}{l}\text { Total number of companies in the } \\
\text { destination city in } 2007\end{array}$ \\
\hline
\end{tabular}

Tab. III Defined variables.

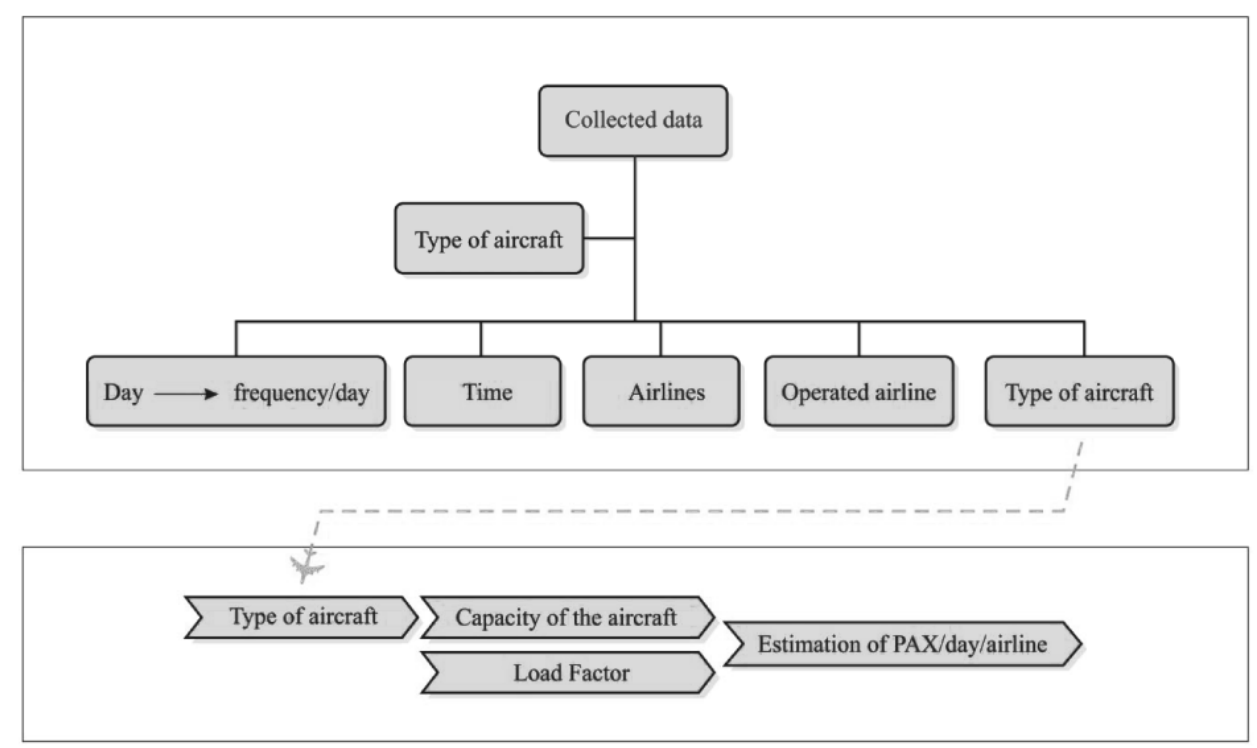

Fig. 1 Part of the process of estimation of passenger demand from the supply data. Data was mainly collected from available sources on the Internet, such as US DOT, U.S. Department of Commerce, Airports Council International or ACI, Boeing, ICAO, IATA and so on. The rest had to be estimated based on statistics, predictions and by indexing.

to geo-economic data. Supply data were collected to fill up the missing demand data that were not obtainable, especially for trips originating from European airports other than Prague Airport.

For the purpose of this research, the supply data of the direct flights was obtained from Expedia [13] and collected in two distinct periods: the summer 
timetable (August 2012) and winter timetable (March 2013) of the airlines. For each flight between a defined airport pair, the following data were collected on a daily basis (for one week in the defined period): operated airlines, co-shared airlines, operated aircraft and their capacity based on configuration of the seats.

The biggest challenge of this research was the collection and estimation of the annual passenger demand from the detected European airports to the selected U.S. airports. All existing scheduled flights between defined airport-pairs had to be collected from available flight databases, an extra sheet in Excel was created for each airport-pair and passenger demand was estimated based on load factors (operated aircraft and flight frequencies).

After completing a database of required data, index methods were used on the core database of input data for further simulation. Additionally, the required statistics data such as population, unemployment rate, total annual passengers of the origin and destination airports, national income and number of companies was collected for future modelling and demand estimation.

Specific values are provided in tables bellow:

\begin{tabular}{|c|c|c|c|}
\hline \multicolumn{2}{|c|}{ BUS $_{i}$ (no.of companies) } & \multicolumn{2}{|c|}{$\mathrm{POP}_{j}$ (population) } \\
\hline BOS & 49667 & AMS & 780559 \\
\hline JFK & 944129 & CDG & 11800000 \\
\hline LAX & 450108 & CPH & 1213822 \\
\hline MIA & 85146 & FRA & 691518 \\
\hline ORD & 255502 & LHR & 14900000 \\
\hline SFO & 105030 & ZRH & 390082 \\
\hline
\end{tabular}

Tab. IV Parameters $\mathrm{BUS}_{i}, \mathrm{POP}_{j}$. Source: [12].

\begin{tabular}{|c|c|c|c|c|c|c|}
\hline D(mi) & BOS & JFK & LAX & MIA & ORD & SFO \\
\hline AMS & 3450 & 3630 & 5560 & 999999 & 4110 & 5460 \\
\hline CDG & 3440 & 3620 & 5650 & 4580 & 4140 & 5570 \\
\hline CPH & 999999 & 999999 & 999999 & 999999 & 4260 & 999999 \\
\hline FRA & 3660 & 3840 & 5790 & 4820 & 4330 & 5680 \\
\hline LHR & 3250 & 3440 & 5440 & 4410 & 3940 & 5350 \\
\hline ZRH & 3730 & 3920 & 5920 & 4870 & 4430 & 5820 \\
\hline
\end{tabular}

Tab. V The distance matrix $\mathbf{D}$ (elements DIS $_{i j}$ ) as gravity model input. Source: [12].

\subsubsection{Searching parameters of gravity model using DE}

$\mathrm{DE}$ is used to determine the following parameters of the gravity model: coefficients $a_{i}$ and $b_{j}, i=1 \ldots n, j=1 \ldots m$ and exponent $x$ in Cheu's formula [3], where:

$n$ is the number of rows in DIS (PAX) = number of origins airport,

$m$ is the number of columns in DIS (PAX) $=$ destination cities. 
Bínová H.: Modified Method of Gravity Model Application...

\begin{tabular}{|c|c|c|c|c|c|c|c|}
\hline $\mathbf{P}$ & BOS & JFK & LAX & MIA & ORD & SFO & Q $_{i_{-} \text {pax }}$ \\
\hline AMS & 89122 & 300857 & 122187 & 0,001 & 102908 & 59937 & 675012 \\
\hline CDG & 72724 & 573733 & 275051 & 139624 & 150323 & 180817 & 1392271 \\
\hline CPH & 0,001 & 0,001 & 0,001 & 0,001 & 69867 & 0,001 & 69867 \\
\hline FRA & 80266 & 401663 & 94956 & 82361 & 245730 & 204670 & 1109646 \\
\hline LHR & 414737 & 1500386 & 357313 & 247136 & 521369 & 255257 & 3296198 \\
\hline ZRH & 65191 & 203929 & 54665 & 100697 & 68727 & 63776 & 556985 \\
\hline D $_{j_{-} \text {pax }}$ & 722040 & 2980569 & 904172 & 569818 & 1158923 & 764457 & $\mathbf{7 0 9 9} \mathbf{9 7 9}$ \\
\hline
\end{tabular}

Tab. VI The matrix $\mathbf{P}$ of estimated number of passengers (elements $\mathrm{PAX}_{i j}$ ). Source: [12].

The individual is a vector with dimension equal to $D=n+m+1$, where the meaning of components is: the first $n$ components are $a_{i}$ coefficients, the next $m$ components are $b_{j}$ coefficients, and the last component is the exponent $x$.

The structure of an individual is: length $D=n+m+1$

\begin{tabular}{|l|l|l|l|l|l|l|l|l|}
\hline$a_{1}$ & $a_{2}$ & $\ldots$ & $a_{n}$ & $b_{1}$ & $b_{2}$ & $\ldots \ldots$ & $b_{m}$ & $x$ \\
\hline
\end{tabular}

Fig. 2 Structure of chromosomes.

If the initial population is generated, then random values are usually generated within a given interval in DE. When a reproduction cycle is executed, new values of the testing vector are tested for membership in the permissible interval (this tests if they are valid; the boundaries are based for example on physical constrains). In our application, the initial individuals are generated randomly with boundaries which are derived from recommended initial values by the iteration method used in gravity model:

$x \quad$ is generated from the range of $x \in\langle 1,3\rangle$,

$a_{i}, b_{j} \quad$ are generated from the range of $a_{i}, b_{j} \in\langle 0,3\rangle$.

During reproduction cycles, the test is not performed to verify if the DE can find optimal parameters outside of recommended range in the classical gravity model.

\section{Fitness function calculation}

An estimation of matrix $\mathbf{T}$ is calculated for each individual using parameters $a_{i}, b_{j}$, $x$. The known $\mathbf{P}$ matrix is divided by the value 200 (average number of passengers per flight) and the number of flights is calculated. The fitness function is total square root error:

$$
\mathrm{FIT}=\sum_{i=1}^{n} \sum_{j=1}^{m}\left(T_{i j}-\operatorname{PAX}_{i j} / 200\right)^{2} .
$$

DE searches for a minimum value of the fitness function.

\section{Parameters of algorithms:}

Algorithm parameters are as follows:

Size of population: $N=1,000$. 
Maximum number of iterations MAX_ITERATIONS $=10.000$ - the algorithm stops if the count of iterations is 10,000 .

Crossing threshold $\mathrm{CR}=0.8$; the value is derived from the recommended value in the literature $[6,9]$.

Mutation constant $F=1$.

The final solution is the best solution over all generations.

\section{Results of DE}

Results are provided for the data presented above (Tab. VI).

\section{Original results}

DE found the following optimal parameters of the gravity model:

$$
\begin{aligned}
& a_{1}=3362.88 \\
& a_{2}=418.21 \\
& a_{3}=138.32 \\
& a_{4}=6899.30 \\
& a_{5}=679.16 \\
& a_{6}=6296.69 \\
& b_{1}=2964.49 \\
& b_{2}=777.79 \\
& b_{3}=2991.06 \\
& b_{4}=4221.19 \\
& b_{5}=1798.43 \\
& b_{6}=9359.23 \\
& x=4.24
\end{aligned}
$$

This table contains input data for the fitness function (6) - distance matrix $\operatorname{PAX}_{i j}$ (Tab. V) divided by 200.

\begin{tabular}{|c|c|c|c|c|c|c|}
\hline P & BOS & JFK & LAX & MIA & ORD & SFO \\
\hline AMS & 446 & 1504 & 611 & 0 & 515 & 300 \\
\hline CDG & 364 & 2869 & 1375 & 698 & 752 & 904 \\
\hline CPH & 0 & 0 & 0 & 0 & 349 & 0 \\
\hline FRA & 401 & 2008 & 475 & 412 & 1229 & 1023 \\
\hline LHR & 2074 & 7502 & 1787 & 1236 & 2607 & 1276 \\
\hline ZRH & 326 & 1020 & 273 & 503 & 344 & 319 \\
\hline
\end{tabular}

Tab. VII Input data - matrix $\mathbf{P}$ (elements $\left.\mathrm{PAX}_{i j} / 200\right)$.

This is a demand matrix $T_{i j}$ as a side result of DE. The matrix contains predicted numbers of flights calculated by (5) using parameters $a_{1}, \ldots, a_{6}, b_{1}, \ldots, b_{6}$, $x$ evolved by the DE. 

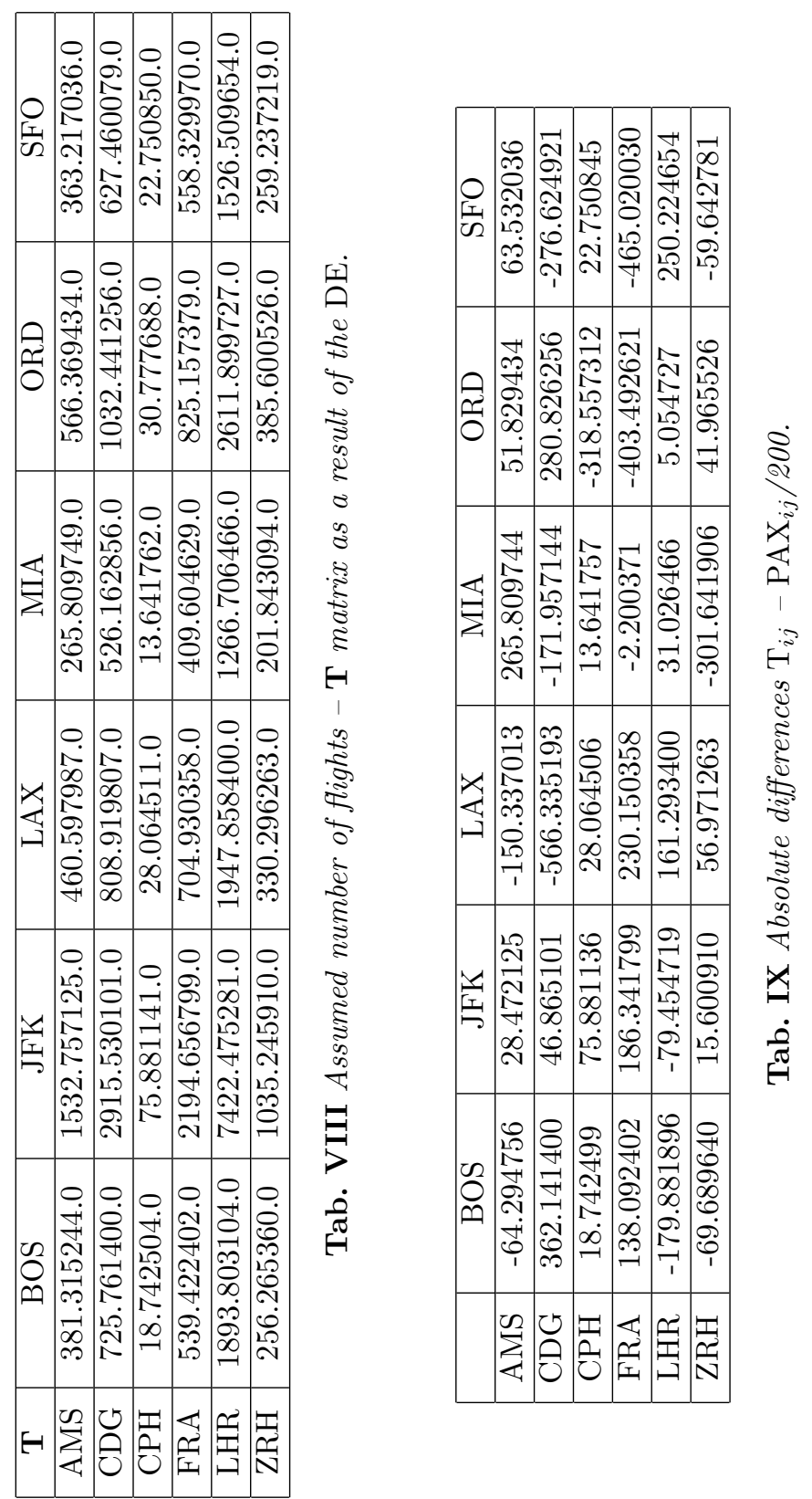
The absolute differences between predicted numbers of flights $T_{i j}$ and input data $\mathrm{PAX}_{i j} / 200$ are provided in Tab. IX.

Relative differences between predicted number of flights $T_{i j}$ and input data $\mathrm{PAX}_{i j} / 200$ are calculated by:

$$
\mathrm{R}_{d i f f}=\frac{T_{i j}-\mathrm{PAX}_{i j} / 200}{\mathrm{PAX}_{i j} / 200} \cdot 100[\%] .
$$

\begin{tabular}{|c|c|c|c|c|c|c|}
\hline & BOS & JFK & LAX & MIA & ORD & SFO \\
\hline AMS & -14.4 & 1.9 & -24.6 & 5316194889.2 & 10.1 & 21.2 \\
\hline CDG & 99.6 & 1.6 & -41.2 & -24.6 & 37.4 & -30.6 \\
\hline CPH & 374849975.5 & 1517622728.7 & 561290114.6 & 272835137.9 & -91.2 & 455016898.4 \\
\hline FRA & 34.4 & 9.3 & 48.5 & -0.5 & -32.8 & -45.4 \\
\hline LHR & -8.7 & -1.1 & 9.0 & 2.5 & 0.2 & 19.6 \\
\hline ZRH & -21.4 & 1.5 & 20.8 & -59.9 & 12.2 & -18.7 \\
\hline
\end{tabular}

Tab. X Relative differences in \%.

The input data for flights between the Copenhagen Airport $(\mathrm{CPH})$ and the airports in Boston (BOS), New York (JFK), Los Angeles (LAX), Miami (MIA), and San Francisco (SFO), and for flights between Amsterdam Airport (AMS) and Miami Airport (MIA) were not obtained and thus the outputs are not relevant. In Tab. VII, this is indicated with "o".

The results provided in Tab. X (relative differences in \%) for the airports specified above are not valid. They are presented here only for informational purposes. Graph at Fig. 3 shows how the fitness function (total square root error) evolved.

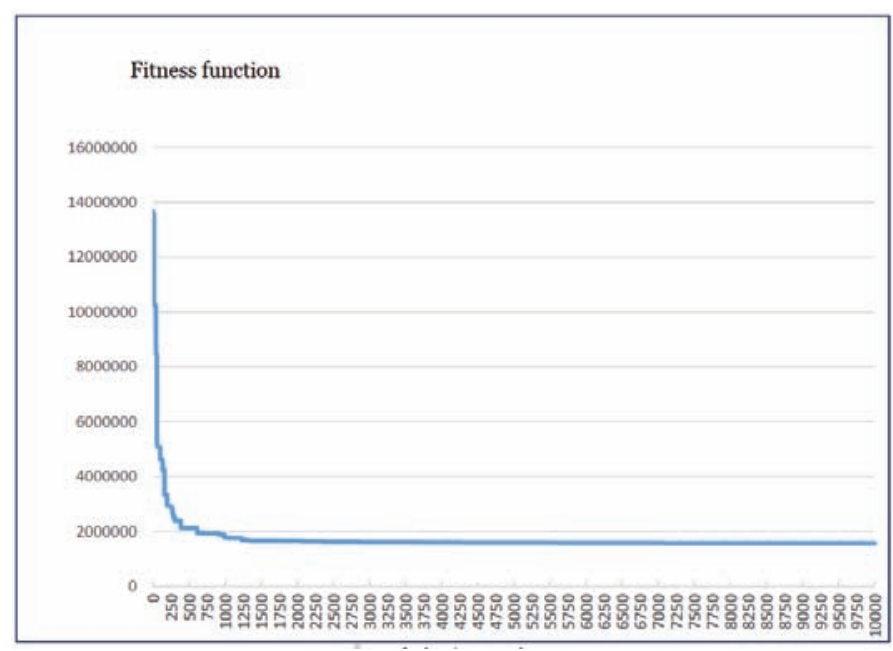

population/generation

Fig. 3 Evolution of the fitness function. 


\section{Conclusion}

The results obtained using the DE methods are more credible. Take, for example, the number of flights between Amsterdam (AMS) and New York (JFK), which is otherwise stated to amount to 100,416 per year, which represents 275 flights per day, and this number appears to be unrealistic.

\begin{tabular}{|l|l|}
\hline \multicolumn{2}{|l|}{ Parameters obtained } \\
by & the DE \\
\hline$a_{1}$ & 3362.88 \\
\hline$a_{2}$ & 418.21 \\
\hline$a_{3}$ & 138.32 \\
\hline$a_{4}$ & 6899.30 \\
\hline$a_{5}$ & 679.16 \\
\hline$a_{6}$ & 6296.69 \\
\hline$b_{1}$ & 2964.49 \\
\hline$b_{2}$ & 777.79 \\
\hline$b_{3}$ & 2991.06 \\
\hline$b_{4}$ & 4221.19 \\
\hline$b_{5}$ & 1798.43 \\
\hline $\mathrm{b}_{6}$ & 9359.23 \\
\hline $\mathrm{X}$ & 4.24 \\
\hline
\end{tabular}

\begin{tabular}{|l|l|}
\hline \multicolumn{2}{|l|}{$\begin{array}{l}\text { Parameters obtained } \\
\text { by }\end{array}$} \\
\hline$a_{1}$ & 16.147 \\
\hline$a_{2}$ & 15.462 \\
\hline$a_{3}$ & 111.577 \\
\hline$a_{4}$ & 16.046 \\
\hline$a_{5}$ & 14.897 \\
\hline$a_{6}$ & 16.318 \\
\hline$b_{1}$ & 0.000002 \\
\hline$b_{2}$ & 0.000002 \\
\hline$b_{3}$ & 0.000002 \\
\hline$b_{4}$ & 0.000002 \\
\hline$b_{5}$ & 0.000001 \\
\hline $\mathrm{b}_{6}$ & 0.000002 \\
\hline $\mathrm{x}$ & 2 \\
\hline
\end{tabular}

Tab. XI Parameters obtained by the DE and by the iterative algorithm.

The above-stated calculations demonstrate how the values of constants $a_{i}$ and $b_{j}, i=1 \ldots n, j=1 \ldots m$ and exponent $x$ can be calculated using the differential evolution method.These constants depend on a number of aspects of the given location and it is the method of their calculation using differential analysis that enables their calibration using the data entered.

Entered data were adopted from [12]. Presented results obviously differ from those published in [12] as DE is used instead of an iterative algorithm. Comparison can show that the predicted demand matrix $\mathbf{T}$ calculated with parameters searched via $\mathrm{DE}$ is more accurate.

If we compare the modified results with values that have been calculated without using the method of differential evolution, it is evident that they vary considerably. However, the original results have not yet been used in practice for the forecast of development of air transportation between specified destinations. The method of differential evolution may bring new knowledge for processing of air traffic forecasts.

\section{Acknowledgement}

The author acknowledges support from the EU-US Atlantis Program. Project Title: Transatlantic Dual Master's Degree Program in Transportation and Logistics Systems (ATL). This project and research is also co-funded by the European Commission's Directorate General for Education and Culture (DG EAC) under Agreement 2010-2843/001-001-CPT EU-US TD. 

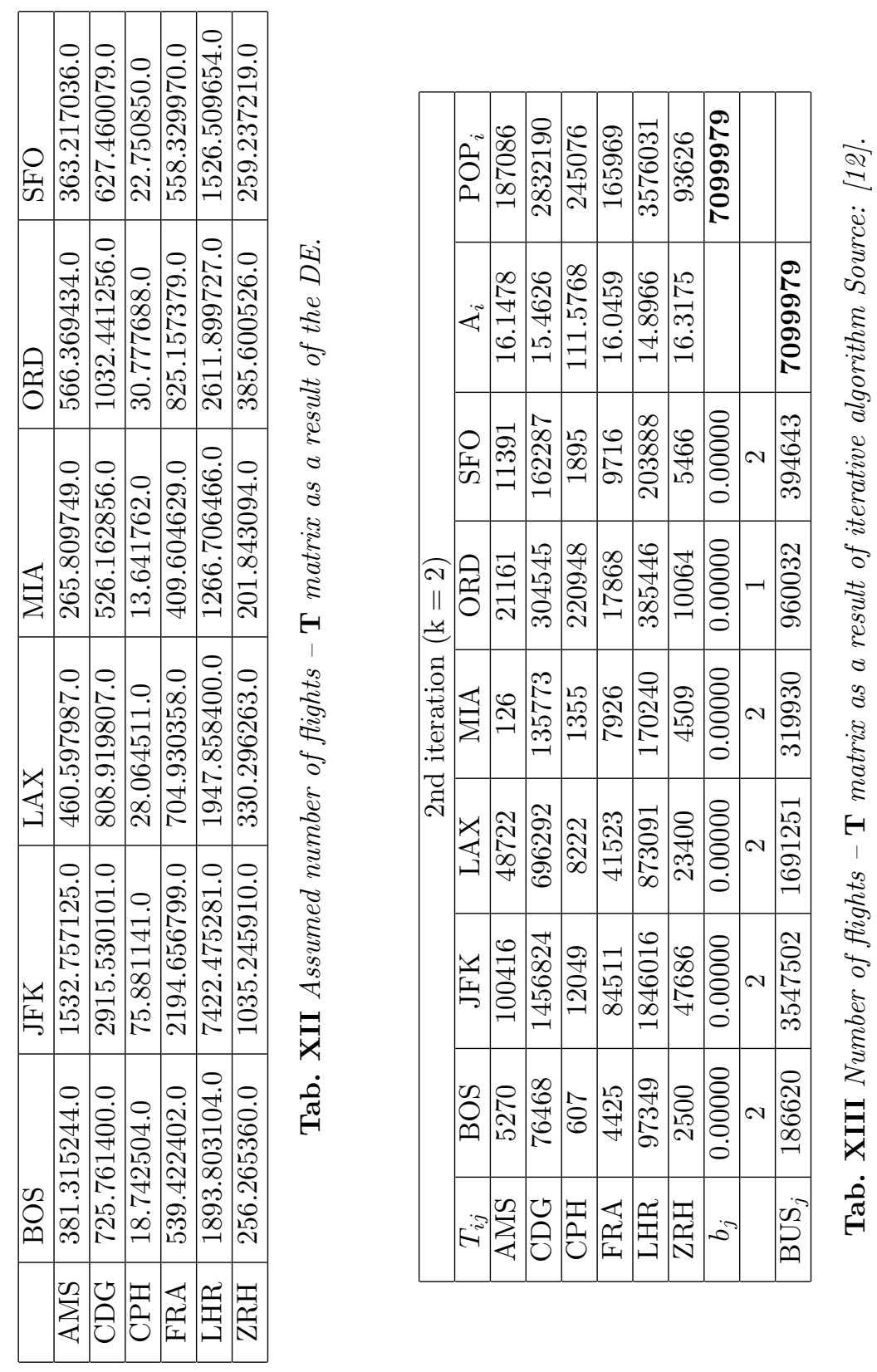


\section{References}

[1] BOEING. Aviation Policy and Geopolitics 2012. Boeing Commercial Airplanes: Seattle. Available from: http://www.boeing.com

[2] CHANG L.-Y. International air passenger flows between pairs of APEC countries: A nonparametric regression tree approach. Journal of Air Transport Management. 20, pp. 4-6, doi: 10.1016/j.jairtraman.2011.04.001.

[3] CHEU R. Trip Distribution, lecture notes distributed in the topic CE 6306 Infrastructure Engineering. University of Texas at El Paso, El Paso, 2012.

[4] FÁBERA V., ZELENKA J., JÁNEŠ V., JÁNEŠOVÁ M. Regular Grammar Transformation Inspired by the Graph Distance Using Ga. Neural Network World. 2011, 21(4), pp. 299-309, doi: 10.14311/NNW.2011.21.018.

[5] FÁBERA V., ZELENKA J., JÁNEŠ V., JÁNEŠOVÁ M. Grammatical evolution and FSM construction. In: Proceedings of the 18th International Conference on Soft Computing, Brno, Czech Republic. MENDEL, 2012.

[6] MAŘÍK V., ŠTĚPÁNKOVÁ O., LAŽANSKÝ J. Umělá inteligence IV. Praha: AV ČR, 2003.

[7] PRG - VÁClAV HAVEL PRAGUE AIRPORT, RUZYNĚ. Destination: Success - Let your story begin in Prague. Prague: Prague Airport. Available from: http://www.prg. aero/Files/letecky-obchod/brozura-letecky-obchod/.

[8] PRG - VÁCLAV HAVEL PRAGUE AIRPORT, RUZYNĚ. Business section. Available from: http://www.prg.aero/en/business-section/

[9] PRICE K. An Introduction to Differential Evolution, New Ideas in Optimization. London: McGraw-Hill, 1999. [10] PRICE K., STORN R. Differential Evolution - A simple evolutionary strategy for fast Optimization. USA, San Francisco: Dr. Dobb's Journal, 1997.

[10] SRINIDHI S. Development of an Airline Traffic Forecasting Model on International Sectors. In: Proceedings of the 5th Annual IEEE International Conference on Automation Science and Engineering, India, Bangalore. IEEE, 2009, pp. 1-6, doi: 10.1109/COASE.2009.5234138.

[11] STRELCOVA K., BÍNA L., CHEU R. Development of Demand Forecasting Model for Transatlantic Air Transportation. In: Proceedings of the INAIR 2013, International Conference on Air Transport, Bratislava, Slovakia. 2013, pp. 126-131.

[12] Wensveen J.G. Air Transportation: A Management Perspective. 6th. ed. Hampshire, England: Ashgate Publishing, Ltd., 2007.

[13] UNITED STATES SECURITIES AND EXCHANGE COMMISSION. Expedia Annual Report 2013. Expedia Inc, Commission file number: 000-51447. Avalaible from: http://www. annualreports . com/Company/3104. 